\title{
Impact of Post-Transplantation Hypomagnesemia on Long-Term Graft and Patient Survival after Transplantation
}

\author{
Ofer Isakov $^{a} \quad$ Bhanu K. Patibandla ${ }^{b}$ Kenneth B. Christopher ${ }^{c}$ Anil Chandraker ${ }^{c, d}$ \\ Tammy Hode, ${ }^{\text {f }}$ \\ aDepartment of Internal Medicine "T", Tel Aviv Souraski Medical Center, Tel Aviv University, Tel Aviv, Israel; \\ ${ }^{b}$ Division of Pulmonary and Critical Care Medicine, Oregon Health and Science University, Portland, OR, USA; \\ 'Renal Division, Brigham and Women's Hospital and Harvard Medical School, Boston, MA, USA; 'Transplant Research \\ Center, Renal Division, Brigham and Women's Hospital and Harvard Medical School, Boston, MA, USA;

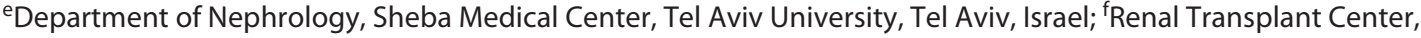 \\ Sheba Medical Center, Tel Aviv University, Tel Aviv, Israel
}

\section{Keywords}

Hypomagenesemia · Calcineurin inhibitors · Renal allograft survival · Mortality

\begin{abstract}
Background: Post-transplant hypomagnesemia is commonly observed among patients prescribed calcineurin inhibitor (CNIs). Methods: We conducted a retrospective single-center analysis (2000-2013,N=726) to examine the association of hypomagnesemia with long-term patient and allograft outcomes in kidney transplant recipients. A median serum magnesium $(\mathrm{Mg}$ ) level of all measured $\mathrm{Mg}$ levels from 1 month to 1 year posttransplant was calculated. Results: For every increase in $\mathrm{Mg}$ of $0.1 \mathrm{mg} / \mathrm{dL}$, the risk for either graft loss or death, overall mortality, and death with a functioning graft increased by $11 \%, 14 \%$, and $12 \%$, respectively ( $p<$ $0.01)$. In a multivariate model, patients with median $\mathrm{Mg}$ level $\geq 1.7 \mathrm{mg} / \mathrm{dL}$ had a reduced overall survival rate (HR 1.57, 95\% $\mathrm{Cl}: 1.04-2.38, p=0.033$ ) compared to those with median Mg level $<1.7 \mathrm{mg} / \mathrm{dL}$. This association was observed in subgroups of patients above 60 years old, in those who had a slow graft function (SGF) and in females. Conclusions: Posttransplant hypomagnesemia is associated with better pa-
\end{abstract}

Karger@karger.com www.karger.com/kbr

Karger"

BOPEN ACCESS
(C) 2022 The Author(s)

Published by S. Karger AG, Basel

This is an Open Access article licensed under the Creative Commons Attribution-NonCommercial-4.0 International License (CC BY-NC) (http://www.karger.com/Services/OpenAccessLicense), applicable to the online version of the article only. Usage and distribution for commercial purposes requires written permission. tient and allograft survival up to 10 years posttransplant. This relationship remained significant after accounting for baseline allograft function, presence of SGF and CNI trough levels.

(C) 2022 The Author(s)

Published by S. Karger AG, Basel

\section{Introduction}

Hypomagnesemia is a common complication in the posttransplant period particularly associated with calcineurin inhibitor (CNIs) use [1-3]. Low magnesium $(\mathrm{Mg})$ blood levels have been associated with hypertension (HTN), metabolic syndrome, progression of atherosclerosis, and ischemic stroke [4-7]. Hypomagnesemia increases the risk of life-threatening arrhythmias in patients with cardiovascular disease (CVD) [8]. Mg deficiency promotes the dysregulation of endothelial cell function, inflammation, and oxidative stress $[9,10]$, while Mg supplementation improves endothelial cell dysfunction in patients with coronary artery disease [11].

Additionally, a higher incidence of hypomagnesemia has been reported among patients with diabetes [12] or with prediabetes hyperglycemia $[13,14]$. Mg supplemen- 
tation to type II diabetic patients resulted in improved glycemic control [15]. Hypomagnesemia early posttransplant was shown to be an independent predictor of new onset diabetes after transplantation [16-18]; however, the association between hypomagnesemia and new onset diabetes after transplantation remains controversial due to conflicting findings $[12,19,20]$.

Several adverse reactions attributed to cyclosporine (CsA) may be secondary to hypomagnesemia induced by renal $\mathrm{Mg}$ wasting. Acquired derangements in $\mathrm{Mg}$ metabolism may contribute to the development of HTN [21]. Renal Mg wasting may also be added to the spectrum of CsA-induced nephropathy as $\mathrm{Mg}$ supplementation ameliorated chronic CsA nephropathy via inhibiting renal mRNA expression of fibrogenic molecules and extracellular matrices [22].

Hypomagnesemia has been broadly associated with negative outcomes but the effect of low serum Mg levels on long-term patient and allograft outcomes in renal transplant recipients is still unclear. We have previously shown a robust relationship between low Mg levels in the first-year posttransplant and better long-term allograft function [23]. Given this somewhat counterintuitive finding and the ample data on the relationship between low Mg levels and cardiovascular risk in the non-transplant population, we decided to investigate the possibility of an association between low $\mathrm{Mg}$ levels posttransplant and graft/patient survival in the kidney transplant population.

\section{Materials and Methods}

\section{Study Design}

This is a retrospective analysis of data gathered from the Research Patient Data Registry system at our institution, in addition to data we collected from clinical records. Biochemical data were retrieved in an automated fashion from the laboratory database and clinical data from electronic medical records. This study was approved by the local Ethics Committee.

\section{Patients}

All patients who underwent kidney transplantation at Brigham and Women's Hospital between January 2000 and September 2013 were evaluated for inclusion in the study and constituted a population of 856 transplants. Exclusion criteria were patients without serum $\mathrm{Mg}$ levels from 1 month to 1 year posttransplant $(n=91)$ including those whose graft failed in the first-year posttransplant $(n=39)$.

\section{Immunosuppression}

Induction therapy consisted of either basiliximab (Simulect Novartis Pharma, Basel, Switzerland), or thymoglobulin (Genzyme, Boston, MA, USA). All patients received corticosteroids, beginning with a single preoperative bolus of $500 \mathrm{mg}$ methylprednisolone intravenously, with gradual tapering to $20 \mathrm{mg}$ oral prednisone at postoperative day 5 . If the patient was a candidate for early steroid withdrawal, the prednisone was continued at 20 mg PO daily until tacrolimus levels reached the therapeutic goal $(>8 \mathrm{ng} / \mathrm{mL}$ ) and then stopped. If the patient did not achieve therapeutic tacrolimus trough concentrations by postoperative day 12 , the prednisone dose was tapered down below $20 \mathrm{mg}$ /day. In patients who were not candidates for early steroid withdrawal, prednisone was tapered down to $5 \mathrm{mg}$ /day within 2 months of transplant.

All patients were started orally on $1 \mathrm{~g}$ mycophenolate mofetil (Cellcept, Roche Pharma, Basel, Switzerland) or $720 \mathrm{mg}$ of mycophenolate sodium (Myfortic, Novartis Pharma, Basel, Switzerland) preoperatively, followed by $2 \times 1 \mathrm{~g} /$ day or $2 \times 720 \mathrm{mg}$ / day, respectively, with a tapering of the dosage depending on individual needs and/or side effects. CNI therapy was started posttransplantation, using mostly tacrolimus, aiming for trough levels of $8-10 \mathrm{ng} / \mathrm{mL}$ in the first 3 months, and $5-8 \mathrm{ng} / \mathrm{mL}$ thereafter. Trough goals were reduced if patients had side effects.

Biopsy-proven acute rejection was treated with three doses of intravenous methylprednisolone (500 $\mathrm{mg}$ daily) on consecutive days. All patients received Pneumocystis jiroveci pneumonia prophylaxis (sulfamethoprimcotrimoxazole or atovoquone). Prophylaxis for cytomegalovirus disease using gancyclovir (Cytovene Roche Pharma) up to 2003 and then valganciclovir (Valcyte, Roche Pharma) was started in all patients.

\section{Laboratory Data}

The following biochemical posttransplantation variables were retrieved from the Research Patient Data Registry system: serum creatinine, calcium, phosphate, intact parathyroid hormone, $\mathrm{Mg}$, and tacrolimus 12-h trough blood levels. Median serum Mg values from 1 month to 1 year posttransplant were calculated using all samples available from this time period. We chose to look at serum $\mathrm{Mg}$ levels no earlier than 1 month posttransplant in order to prevent the confounding effect of delayed or slow graft function (SGF) and the early use of diuretics on Mg blood levels. Apart from the median $\mathrm{Mg}$, the mean values over this period were also recorded. As the mean values yielded similar results to median $\mathrm{Mg}$, we report only the results based on the median. The coefficient of variation, a standardized measure of dispersion, was calculated for $\mathrm{Mg}$ measurements from 1 month to 1 year posttransplant by dividing the measurements standard deviation by the mean.

The presence or absence of SGF was determined based on whether serum creatinine on postoperative day 5 was above $3 \mathrm{mg} /$ $\mathrm{dL}$ (presence of SGF) or $\leq 3$ (absence of SGF). We also retrieved iPTH, calcium and phosphate levels at 3 months posttransplant (or within the range of 2-4 months posttransplant, the closest value available to 3 months posttransplant) and at 1 year posttransplant (or within the range of 9-15 months posttransplant, the closest value available to 1 year posttransplant).

Median tacrolimus $12 \mathrm{~h}$ trough blood levels were calculated based on all trough levels available from 1 month to 1 year posttransplant in order to associate the tacrolimus trough with serum $\mathrm{Mg}$ within the same time period. Both the median and mean trough levels of tacrolimus from 1 month to 1 year posttransplant were recorded. As the results were similar, we report only the results based on the median. 
Serum creatinine levels were retrieved at 3 months posttransplant ( 3 months \pm 2 weeks posttransplant). Glomerular filtration rate was calculated according to the following CKD Epi formula: $\mathrm{GFR}=141 \times \min (\mathrm{Scr} / \mathrm{k}, 1)^{\alpha} \times \max (\mathrm{Scr} / \mathrm{k}, 1)^{-1.209} \times 0.993^{\text {Age }} \times 1.018$ $\times 1.159$ [if black] $(K=0.7$ if female, 0.9 if male; $\alpha=-0.329$ if female, -0.411 if male; $\min =$ the $\operatorname{minimum}$ of $S c r / k$ of $1 ; \max =$ the $\max -$ imum of Scr/k or 1).

\section{Study Assessments}

Based on the electronic patient medical records, details on the following relevant items were collected: age, gender, race, transplant type, type of induction treatment, medical history (specifically history of hypertension [HTN], heart failure [HF], or cardiovascular disease [CVD]), rejection episodes from 1 month to 1 year posttransplant and use of any loop diuretics from 1 month to 1 year posttransplant. The nature of the original kidney disease was noted as either "diabetic nephropathy" or "other."

\section{Primary Outcome}

Our primary outcome was the composite of either death or graft loss during the posttransplant follow-up. We also looked at other secondary outcomes, including overall survival, death censored graft loss, and death with a functioning graft which have occurred during the study period.

\section{Statistical Analysis}

Descriptive statistics were expressed as percentages for categorical data or mean $( \pm S D)$ for continuous variables. Differences in baseline characteristics between the groups were tested using $\chi^{2}$ for the categorical variables or $t$ test for the continuous variables.

We assessed the association between $\mathrm{Mg}$ level and risk of graft loss and patient's death using Kaplan-Meier curves and the logrank test, followed by multivariable Cox proportional hazards analysis adjusted for age, gender, race, transplant type, induction therapy, pretransplant diabetes, coefficient of variation for $\mathrm{Mg}$ blood levels, median tacrolimus $12 \mathrm{hr}$ trough levels, presence of SGF and baseline allograft function, which was derived from the calculated GFR at 3 months posttransplant. Multivariable analysis was performed using only patients without missing data in any of the aforementioned confounders that were treated with CNIs and when data regarding induction therapy were available ( $80 \%$ of patients; $N=579$ ).

A $p$ value of less than 0.05 was considered statistically significant. The Bonferroni method was used to set the $p$ value threshold for multiple comparisons. The proportional hazards assumption was tested using the cox.zph function from the survival R package. Data were analyzed using R version 3.5.2 (http://www.r-project. org).

\section{Results}

Seven hundred twenty-six transplants (405 men and 321 women) of the original population of 856 transplants fulfilled the inclusion criteria. Of these, 407 (56\%) had median $\mathrm{Mg}$ levels from 1 month to 1 year posttransplant below 1.7 and 319 (44\%) had median Mg levels equal to or above 1.7 (high Mg group).

Post-Transplant Hypomagnesemia

\section{Univariate Comparison Low Mg versus High $M g$ Groups}

Pre- and posttransplantation clinical and biochemical parameters comparing the low and high $\mathrm{Mg}$ groups are presented in online supplementary Table 1 (see www. karger.com/doi/10.1159/000522233 for all online suppl. material). Mean age was $50.7 \pm 13.6$ years in the low $\mathrm{Mg}$ group and $51.9 \pm 13.4$ in the high $\mathrm{Mg}$ group. $11.3 \%$ of patients in the low $\mathrm{Mg}$ group and $16.9 \%$ in the high $\mathrm{Mg}$ group had ESRD secondary to diabetes.

Patients with low $\mathrm{Mg}$ had higher median and mean tacrolimus blood levels from 1 month to year posttransplant $(p<0.0001)$ and lower phosphate levels at 3 months $(p=0.000536)$ and 1 year $(p<0.0001)$ posttransplant compared to patients with high $\mathrm{Mg}$ (see online suppl. Table 1). There were more rejection episodes from 1 month to 1 year posttransplant in the low compared to the high Mg group, but the difference between the groups was not statistically significant. Medical history of HTN, HF, or CVD was also not significantly different between the groups. Due to the association of loop diuretics with increased urinary $\mathrm{Mg}$ excretion [24], we looked at the use of loop diuretics from 1 month to 1 year posttransplant. The use of loop diuretics was higher in the high Mg group than the low Mg group (25.4\% compared to $15.7 \%$ of the patients used PO loop diuretics [ $p=0.00169]$ and $17.2 \%$ compared to $7.9 \%$ of the patients were treated with intravenous loop diuretics [ $p=0.00018]) .32 .2 \%$ of the patients in the low Mg group had SGF compared to $41.1 \%$ in the high $\mathrm{Mg}$ group $(p=0.0166)$. Baseline allograft function derived from GFR at 3 months posttransplant was higher in the low compared to the high Mg group (54.1 \pm 17.6 vs. $49 \pm 18.1 ; p=0.0004)$. Other nonsignificant differences between the variables in the two groups were the prevalence of ESRD attributed to diabetes, transplant type, type of induction, $\mathrm{Ca}$, and PTH blood levels.

\section{Graft and Patient Survival Analyses}

Patients were followed for up to 120 months posttransplant with a mean follow-up time of 50.1 months (median follow-up time of 76 and 47 months for the low and high Mg groups, respectively). During this period, 35 cases in the high $\mathrm{Mg}$ group (11.4\%) and 49 in the low $\mathrm{Mg}$ group (12.1\%) lost their grafts $(p=0.815) .54(17.6 \%)$ and 65 (16\%) patients died in the high and low Mg groups, respectively $(p=0.613)$.

In a univariate Kaplan-Meier survival analysis, the rate of death-censored graft failure was not statistically different between the groups $(p=0.171)$. When considering a combined outcome of either death or graft loss, the over- 

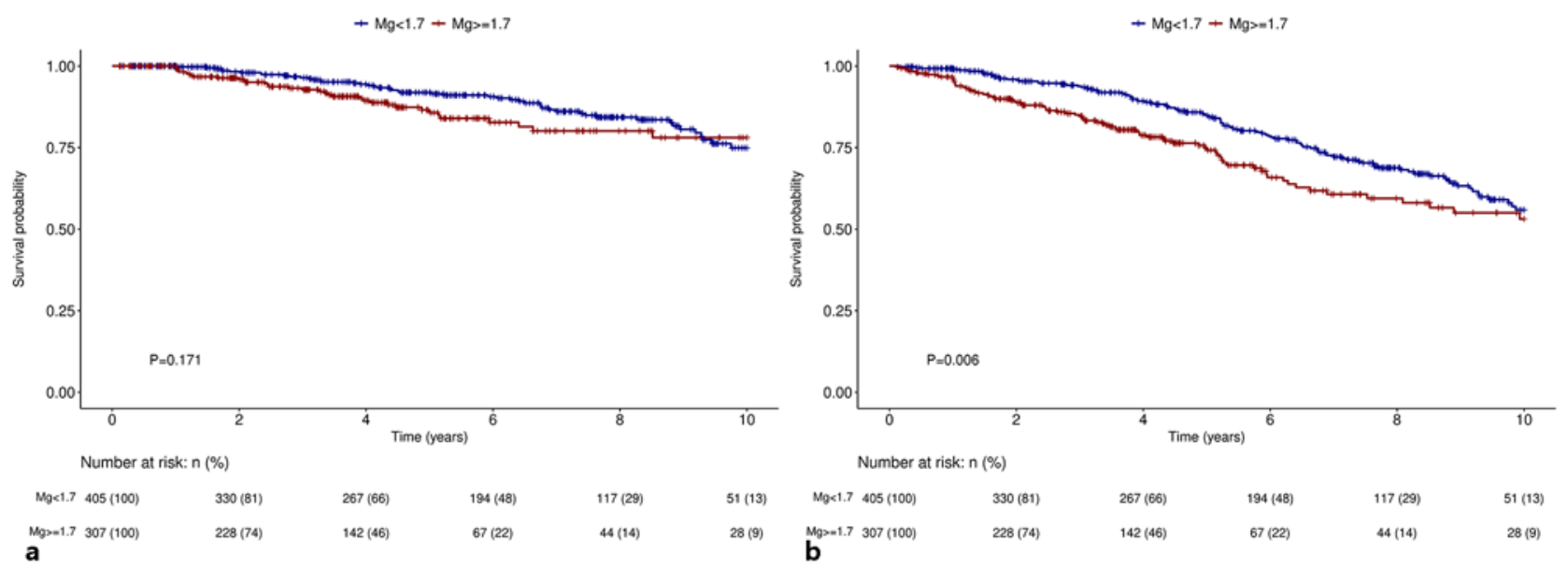

Fig. 1. Univariate Kaplan-Meier curves for death-censored graft survival (a), graft loss, or death (b). a, b Comparisons of survival between the high and low Mg groups with log-rank $p$ values of 0.171 and 0.006 , respectively.

all survival rate was higher in the low Mg group compared to the high Mg groups ( $p=0.006$ ) (see Figure 1). Patient survival was statistically different between the high and low Mg groups for overall survival $(p=0.012)$ and for death with a functioning graft $(p=0.017)$ (see Figure 2).

In a multivariate Cox regression hazard model adjusted for age, gender, race, transplant type, induction therapy, ESRD secondary to diabetes, coefficient of variation in $\mathrm{Mg}$ blood levels, median CNI trough levels, presence of SGF, and baseline allograft function increased Mg level posttransplant was a significant independent predictor for overall mortality (hazard ratio of $1.57,95 \%$ CI: $1.04-$ $2.38, p=0.033$ for the high $\mathrm{Mg}$ group compared to the low $\mathrm{Mg}$ group). Among the other variables included in the analysis, age, induction therapy, ESRD secondary to diabetes, and coefficient of variation in $\mathrm{Mg}$ blood levels were independently associated with patient survival. Mg level $\geq 1.7 \mathrm{mg} / \mathrm{dL}$ was not significantly associated with graft loss when death was censored or included in the analysis ( $p=0.514$ ). Coefficient of variation for $\mathrm{Mg}$ blood levels, age, and baseline allograft function were independently associated with allograft outcomes (see Table 1).

In a multivariate Cox regression hazard model, when the median $\mathrm{Mg}$ was included as a continuous variable, for every increase in $\mathrm{Mg}$ of $0.1 \mathrm{mg} / \mathrm{dL}$, the risk for death was $14 \%$ higher (HR of 1.14, 95\% CI: $1.04-1.23, p=0.004$ ). The risk for either death or graft loss and death with a functioning graft increased by $11 \%$ and $12 \%$, respectively, for every increase in Mg blood levels of $0.1 \mathrm{mg} / \mathrm{dL}$ (HR of 1.11, 95\% CI: $1.04-1.19, p=0.003$ and HR of $1.12,95 \%$ CI: $1.02-1.23, p=0.021$, respectively). For other variables associated with allograft and patient outcomes, see Table 2 .

\section{Kaplan-Meyer Survival Analyses for Multiple Mg \\ Blood Levels}

To better show the association of Mg blood levels with patient and allograft outcomes, we divided our cohort into 3 different groups according to median $\mathrm{Mg}$ blood levels from 1 month to 1 year posttransplant as follows: a total of 559 patients with median $\mathrm{Mg}$ blood levels between 1.3 and $1.8 \mathrm{mg} / \mathrm{dL}, 97$ and 56 participants with median Mg blood levels $\leq 1.3 \mathrm{mg} / \mathrm{dL}$ and $\geq 1.8 \mathrm{mg} / \mathrm{dL}$, respectively. During a follow-up time of up to 120 months posttransplant, 14 cases in the high $\mathrm{Mg}$ groups (14.4\%), 63 in the moderate $\mathrm{Mg}$ groups (11.27\%) and 7 in the low Mg groups (12.5\%) lost their grafts $(p=0.6273)$. Of the sample, $23(23.7 \%), 88$ $(15.7 \%)$, and $48(14.2 \%)$ patients died in the high, moderate and low Mg groups, respectively ( $p=0.147$ ). The combined outcome of graft loss or death was significantly different between the groups $(p=0.003)$. Specifically, risk was greater for the high Mg group $>1.8 \mathrm{mg} / \mathrm{dL}$ and lower for the low $\mathrm{Mg}$ group $<1.3 \mathrm{mg} / \mathrm{dL}$ compared to those with median $\mathrm{Mg}$ blood levels between 1.3 and $1.8 \mathrm{mg} / \mathrm{dL}$. The risk for overall survival was also significantly different between the groups $(p=0.006)$. The variance between the groups remained sig- 


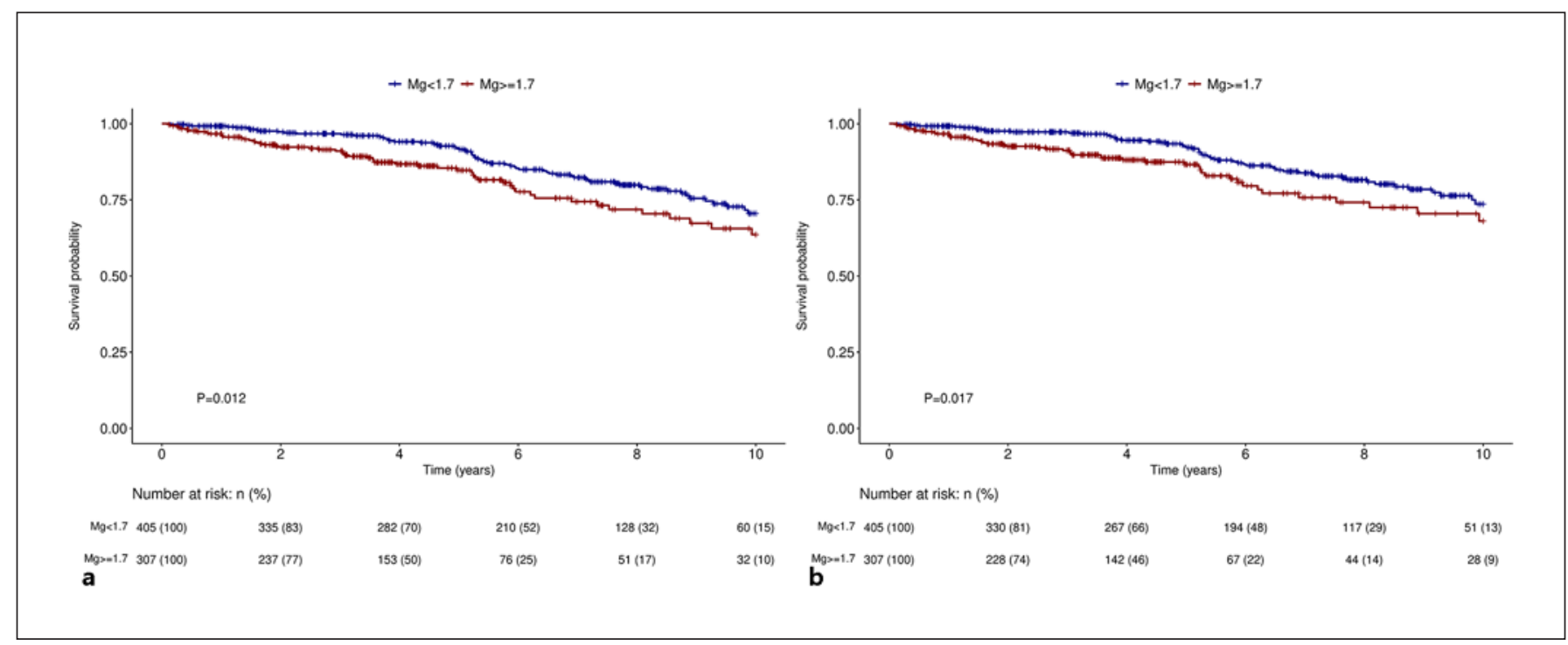

Fig. 2. Univariate Kaplan-Meier curve for death (a), death with a functioning graft (b) showing comparisons of survival between the high and low Mg groups with log-rank $p$ values of 0.012 and 0.017 , respectively.

Table 1. Multivariate Cox regression hazard models when $\mathrm{Mg}$ is a categorical variable

\begin{tabular}{|c|c|c|c|c|}
\hline & $\begin{array}{l}\text { Death censored graft } \\
\text { survival } \\
\text { HR }(95 \% \mathrm{Cl})\end{array}$ & $\begin{array}{l}\text { Graft loss or death } \\
\text { HR }(95 \% \mathrm{Cl})\end{array}$ & $\begin{array}{l}\text { Overall survival } \\
\mathrm{HR}(95 \% \mathrm{Cl})\end{array}$ & $\begin{array}{l}\text { Death with a } \\
\text { functioning graft } \\
\mathrm{HR}(95 \% \mathrm{Cl})\end{array}$ \\
\hline Mg coefficient of variation 1 month to 1 year & $1.05(1.01,1.09)^{*}$ & $1.05(1.02,1.08)^{* * *}$ & $1.05(1.01,1.08)^{* *}$ & $1.05(1.01,1.09)^{* *}$ \\
\hline Age (increase in 1 year) & $0.98(0.96,0.99)^{*}$ & $1.01(1.0,1.03)^{*}$ & $1.05(1.03,1.07)^{* * *}$ & $1.05(1.03,1.08)^{* * *}$ \\
\hline Female (vs. male) & $1.05(0.64,1.73)$ & $1.06(0.76,1.48)$ & $1.12(0.74,1.68)$ & $1.06(0.68,1.66)$ \\
\hline Black & $1.71(0.95,3.08)$ & $1.15(0.77,1.74)$ & $0.81(0.49,1.36)$ & $0.78(0.44,1.39)$ \\
\hline Other & $1.53(0.80,2.92)$ & $1.14(0.73,1.79)$ & $0.78(0.43,1.41)$ & $0.89(0.47,1.69)$ \\
\hline \multicolumn{5}{|l|}{ Transplant type } \\
\hline DCD/ECD versus LRD/LURD & $0.97(0.43,2.19)$ & $1.19(0.71,2.00)$ & $1.62(0.86,3.03)$ & $1.42(0.71,2.84)$ \\
\hline$S C D$ versus $L R D / L U R D$ & $0.75(0.38,1.48)$ & $1.15(0.74,1.79)$ & $1.49(0.87,2.57)$ & $1.55(0.85,2.82)$ \\
\hline Median tacrolimus trough levels 1 month to 1 year & $0.91(0.79,1.06)$ & $0.97(0.88,1.06)$ & $1.04(0.93,1.16)$ & $1.01(0.89,1.14)$ \\
\hline ESRD d/t diabetes versus other etiologies & $1.05(0.53,2.06)$ & $1.35(0.91,2.03)$ & $1.63(1.03,2.59)^{*}$ & $1.68(1.01,2.79)^{*}$ \\
\hline SGF versus no SGF & $0.96(0.51,1.79)$ & $1.02(0.69,1.50)$ & $1.02(0.65,1.61)$ & $1.11(0.68,1.82)$ \\
\hline eGFR 3-month increase in $1 \mathrm{~mL} / \mathrm{min}$ & $0.97(0.95,0.99)^{* * *}$ & $0.98(0.97,0.99)^{* * *}$ & $0.99(0.97,1.00)$ & $0.99(0.98,1.01)$ \\
\hline
\end{tabular}

The results shown in the table were derived from 4 separate multivariate cox regression hazard models; each of them adjusted for the following covariates: $\mathrm{Mg}$ coefficient of variance, age, race, gender, transplant type, induction therapy, mean CNI, trough level, ESRD, secondary to diabetes, presence of SGF, and baseline eGFR. ${ }^{*} p<0.05 .{ }^{* *} p<0.01 .{ }^{* * *} p<0.001$. 


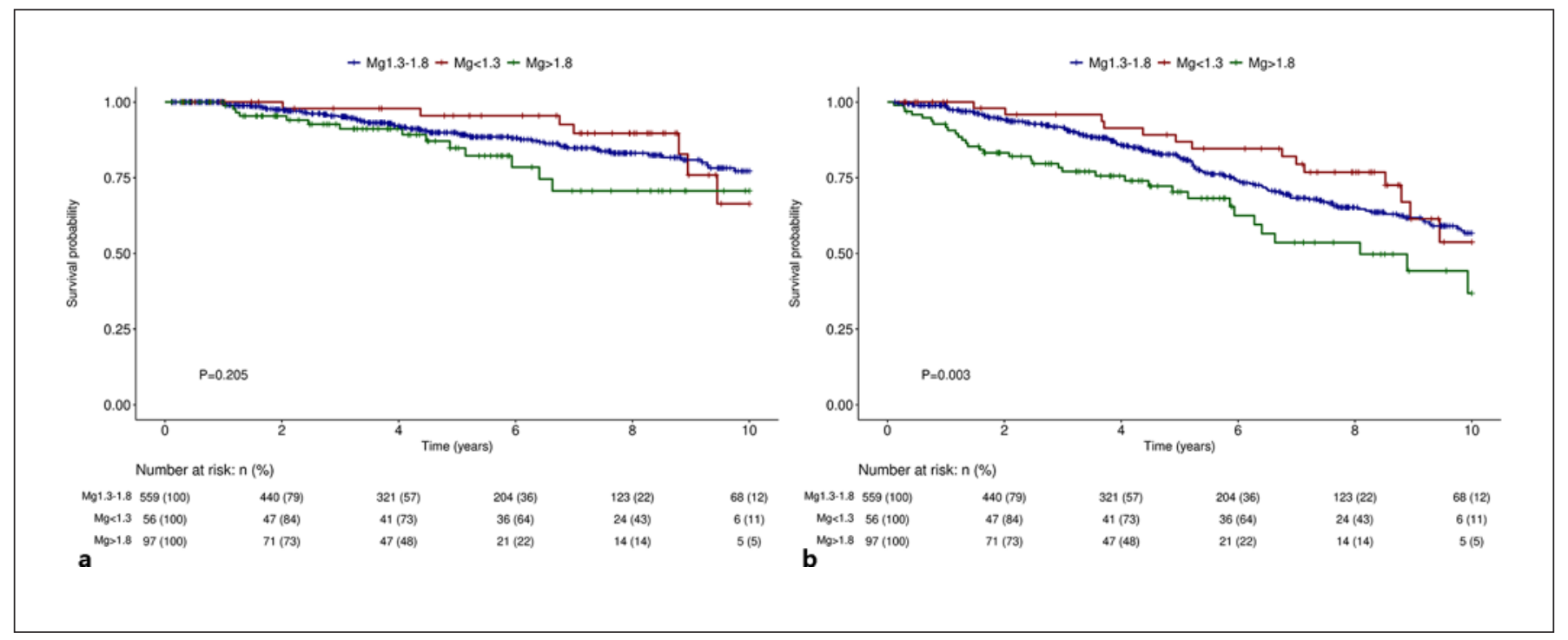

Fig. 3. Univariate Kaplan-Meier curves for death-censored graft survival (a), graft loss or death (b). a, b Comparisons of survival between the high, moderate, and low Mg groups with log-rank $p$ values of 0.205 and 0.003 , respectively.

Table 2. Multivariate Cox regression hazard models with $\mathrm{Mg}$ as a continuous variable

\begin{tabular}{|c|c|c|c|c|}
\hline & $\begin{array}{l}\text { Death censored } \\
\text { graft survival } \\
\mathrm{HR}(95 \% \mathrm{Cl})\end{array}$ & $\begin{array}{l}\text { Graft loss or death } \\
\text { HR }(95 \% \mathrm{Cl})\end{array}$ & $\begin{array}{l}\text { Overall survival } \\
\text { HR }(95 \% \mathrm{Cl})\end{array}$ & $\begin{array}{l}\text { Death with a } \\
\text { functioning graft } \\
\mathrm{HR}(95 \% \mathrm{Cl})\end{array}$ \\
\hline Mg coefficient of variation 1 month to 1 year & $1.05(1.01,1.09)^{*}$ & $1.05(1.02,1.08)^{* * *}$ & $1.04(1.01,1.08)^{*}$ & $1.05(1.01,1.09)^{* *}$ \\
\hline Age (increase in 1 year) & $0.98(0.96,1.00)$ & $1.02(1.00,1.03)^{*}$ & $1.05(1.03,1.07)^{* * *}$ & $1.06(1.03,1.08)^{* * *}$ \\
\hline Female (vs. male) & $1.06(0.64,1.75)$ & $1.08(0.78,1.51)$ & $1.16(0.77,1.74)$ & $1.09(0.70,1.71)$ \\
\hline White & Reference & & & \\
\hline Black & $1.81(1.0,3.25)^{*}$ & $1.20(0.80,1.80)$ & $0.86(0.52,1.43)$ & $0.83(0.47,1.46)$ \\
\hline Other & $1.53(0.80,2.93)$ & $1.15(0.73,1.80)$ & $0.79(0.43,1.43)$ & $0.89(0.47,1.70)$ \\
\hline \multicolumn{5}{|l|}{ Transplant type } \\
\hline DCD/ECD versus LRD/LURD & $1.00(0.44,2.26)$ & $1.19(0.71,2.01)$ & $1.60(0.85,3.01)$ & $1.40(0.69,2.81)$ \\
\hline SCD versus LRD/LURD & $0.74(0.37,1.45)$ & $1.12(0.72,1.75)$ & $1.43(0.82,2.47)$ & $1.50(0.82,2.74)$ \\
\hline Median tacrolimus trough levels 1 month to 1 year & $0.95(0.81,1.10)$ & $0.99(0.89,1.09)$ & $1.06(0.95,1.19)$ & $1.02(0.90,1.16)$ \\
\hline ESRD d/t diabetes versus other etiologies & $0.93(0.47,1.86)$ & $1.26(0.84,1.90)$ & $1.55(0.97,2.47)$ & $1.62(0.97,2.69)$ \\
\hline SGF versus no SGF & $0.95(0.50,1.79)$ & $1.01(0.68,1.50)$ & $1.04(0.66,1.65)$ & $1.11(0.68,1.84)$ \\
\hline eGFR 3-month increase in $1 \mathrm{~mL} / \mathrm{min}$ & $0.97(0.96,0.99)^{* *}$ & $0.98(0.97,0.99)^{* *}$ & $0.99(0.98,1.00)$ & $0.99(0.98,1.01)$ \\
\hline
\end{tabular}

Note: The results shown in the table were derived from 4 separate multivariate cox regression hazard models; each of them adjusted for the following covariates: age, race, gender, transplant type, induction therapy, mean CNI, trough level, ESRD, secondary to diabetes, presence of SGF, and baseline eGFR. ${ }^{*} p<0.05 .^{* *} p<0.01 .{ }^{* * *} p<0.001$. 


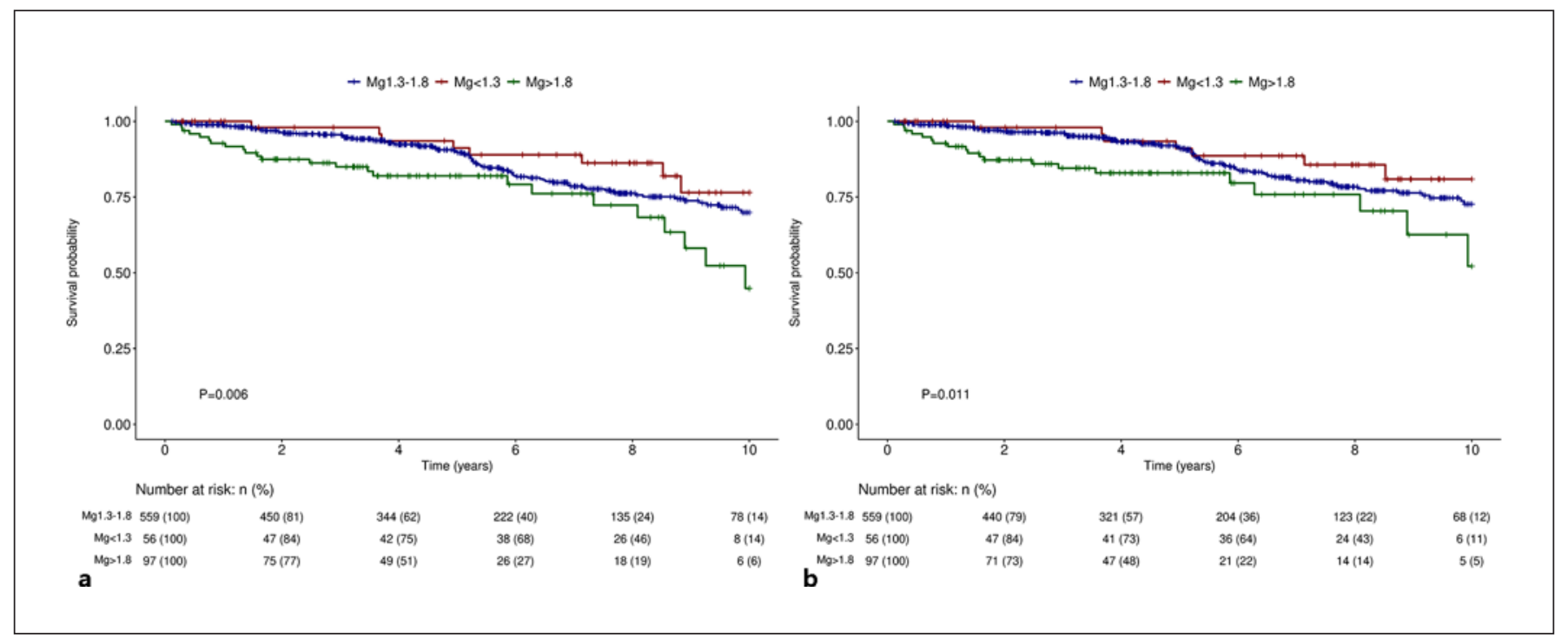

Fig. 4. Univariate Kaplan-Meier curve for death (a) and death with a functioning graft (b) showing comparisons of survival between the high, moderate, and low Mg groups with log-rank $p$ values of 0.006 and 0.011 , respectively.

Table 3. Multivariate Cox regression hazard models in patient subgroups

\begin{tabular}{llll}
\hline Subgroups & $\begin{array}{l}\text { Graft loss or death } \\
\text { HR }(95 \% \mathrm{Cl}) \\
\text { increase in Mg of } 0.1 \mathrm{mg} / \mathrm{dL}\end{array}$ & $\begin{array}{l}\text { Overall survival } \\
\text { HR }(95 \% \mathrm{Cl}) \\
\text { increase in Mg of } 0.1 \mathrm{mg} / \mathrm{dL}\end{array}$ & $\begin{array}{l}\text { Death with a functioning graft } \\
\mathrm{HR}(95 \% \mathrm{Cl}) \\
\text { increase in Mg of } 0.1 \mathrm{mg} / \mathrm{dL}\end{array}$ \\
\hline Age $>60(n=169)$ & $1.21(1.06,1.34)^{* *}$ & $1.25(1.10,1.43)^{* * *}$ & $1.24(1.07,1.43)^{* *}$ \\
Age $\leq 60(n=410)$ & $1.08(0.99,1.18)$ & $1.08(0.95,1.23)$ & $1.06(0.91,1.23)$ \\
Deceased donors $(n=256)$ & $1.14(1.05,1.24)^{* *}$ & $1.16(1.05,1.28)^{* *}$ & $1.14(1.02,1.27)^{*}$ \\
Living donors $(n=323)$ & $1.10(0.96,1.27)$ & $1.08(0.89,1.31)$ & $1.05(0.85,1.3)$ \\
With SGF $(n=203)$ & $1.15(1.05,1.25)^{* *}$ & $1.22(1.1,1.38)^{* * *}$ & $1.22(1.1,1.4)^{* * *}$ \\
Without SGF $(n=376)$ & $1.07(0.95,1.2)$ & $1.03(0.90,1.18)$ & $0.96(0.82,1.13)$ \\
Females $(n=259)$ & - & $1.29(1.14,1.47)^{* * *}$ & $1.28(1.11,1.47)^{* * *}$ \\
Males $(n=320)$ & $1.06(0.97,1.18)$ & $1.03(0.89,1.19)$ & $1.0(0.85,1.17)$ \\
\hline
\end{tabular}

Note: The results shown in the table were derived from 8 separate regression models; each of them adjusted for the following covariates: Mg coefficient of variance, age, race, gender, transplant type, induction therapy, mean $\mathrm{CNI}$, trough level, ESRD, secondary to diabetes, presence of SGF, and baseline eGFR. ${ }^{*} p<0.05 .{ }^{* *} p<0.01$. ${ }^{* * *} p<$ 0.001 .

nificant for death with a functioning graft $(p=0.011)$ (see Figures 3 and 4). In multivariate Cox regression hazard models, there was no significant association between the 3 Mg blood levels and allograft and patient outcomes.

\section{Subgroup Analyses}

To account for the possibility that higher Mg blood levels are a consequence of reduced renal allograft function, we examined the patient subgroups with and with- out SGF and those who received a transplant from a living versus a deceased donor separately. We also conducted subgroup analyses of patients aged above or below 60 and separately for females and males. For every increase in $\mathrm{Mg}$ of $0.1 \mathrm{mg} / \mathrm{dL}$, the risk for an outcome of either graft loss or death was $21 \%, 14 \%$, and $15 \%$ higher in RTR above 60 years of age, in patients who had a deceased donor renal transplant and in those with SGF, respectively. This association was not significant after correcting for multiple 


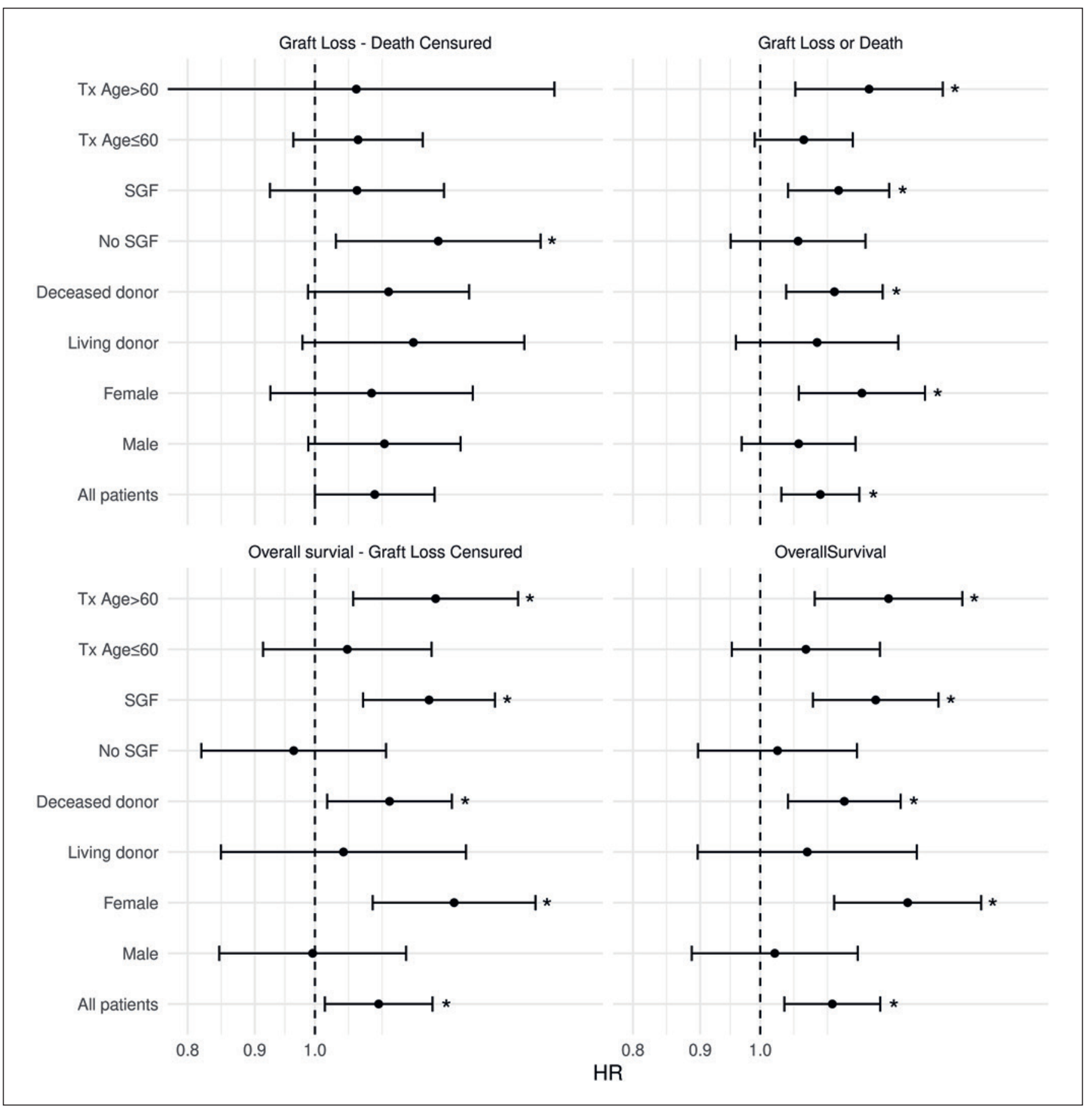

Fig. 5. Forest plot of cox regression multivariate analyses in the high versus low $\mathrm{Mg}$ groups in patient subgroups.

hypothesis. As proportional hazards could not be assumed for the graft loss or death in the female subgroup analysis, this analysis was excluded from the study. We did not find a significant association between $\mathrm{Mg}$ levels and either graft loss or death in subgroups of patients aged $\leq 60$ years, in those who received a living renal transplant, in RTR without SGF and in males (see Table 3 for the results of Cox hazard models when $\mathrm{Mg}$ is a continuous variable). The risk of death and death with a functioning graft increased by $25 \%$ and $24 \%$, respectively, for ev- 
ery increase in $\mathrm{Mg}$ of $0.1 \mathrm{mg} / \mathrm{dL}$ in patients above 60 years of age. After correction for multiple comparisons, $\mathrm{Mg} \mathrm{lev-}$ els were associated with overall survival in patients with SGF, in females and in those aged above 60 and with death with a functioning graft in patients with SGF and in females. Mg blood levels were not associated with overall survival and with death with a functioning graft in subgroups of patients aged $\leq 60$ years, in RTR who had a living transplant, in those without SGF and in males. For all other results of Cox regression models when $\mathrm{Mg}$ is a continuous variable, see Table 3 and Figure 5.

\section{Discussion}

Our results indicate that hypomagnesemia from 1 to 12 months posttransplant is independently associated with a better long-term patient and renal allograft survival. The risk of overall mortality and for death with a functioning graft was more than $50 \%$ higher in the high $\mathrm{Mg}$ group than the low Mg group. The risk of a combined outcome of either graft loss or death was $10 \%$ higher for every increase of $0.1 \mathrm{mg} / \mathrm{dL}$ in $\mathrm{Mg}$ blood levels. In a multilevel univariate analysis with 3 different categories for Mg blood levels, graft loss and mortality were significantly different between the groups. We could not show an independent association in a multivariate analysis probably due to the small number of patients included in the high and low Mg groups. Subgroup analysis revealed an association between $\mathrm{Mg}$ blood levels and overall survival in patients above 60 years of age, in RTR with SGF and in females. The differentiation we observed between the subgroup's points to an association between hypomagnesemia early posttransplant with better graft and patient survival in those with less favorable recipient characteristics (older ones), in those with SGF and in females, as opposed to younger recipients, recipients with immediate graft function and in males. It is possible that we could show an association between hypomagnesemia and allograft and patient outcomes in these subgroups due to higher rates of graft loss and mortality when recipients were older, had SGF and were women compared to when recipients were younger, did not have SGF and were men. Although the high rate of hypomagnesemia among renal transplant recipients, our study is the first to show the relationship between $\mathrm{Mg}$ blood levels early posttransplant and long-term patient and allograft survival.

The association between the use of CNI and patient/ allograft survival disappeared after adjusting for $\mathrm{Mg} \mathrm{lev-}$ els in the multivariate model (Tables 1,2). This finding suggests that the CNI effect on patient and renal graft outcomes is, at least in part, secondary to hypomagnesemia.

CNIs reduce the abundance of key divalent cation transport proteins, expressed along the distal convoluted tubule (DCT), causing renal Mg wasting [25]. The transcript for the transient receptor potential melastatin 6 , a primary Mg channel in the DCT, was reduced by tacrolimus treatment [26]. Deletion of FKBP12 in adult mice, which prevented the ability of tacrolimus to inhibit calcineurin, provided complete protection from tacrolimus toxicity. This finding supports the hypothesis that calcineurin itself plays a central role in modulating divalent cation transport proteins along the distal tubule [27].

While nearly all of the data on CNI toxicity is related to CsA, we specifically looked at the association between tacrolimus-induced hypomagnesemia to patient and graft survival $[22,28-30]$. It is possible that the mechanism of tacrolimus-induced nephrotoxicity is totally different than for CsA, possibly weaker and not mediated via hypomagnesemia.

Our findings are surprising given the vast literature linking hypomagnesemia with negative outcomes. Few other publications support our findings. Data from a recent double-blind randomized study of 54 hemodialysis (HD) patients reported that $\mathrm{Mg}$ supplementation did not improve endothelial function [31]. In addition, Tamashiro et al. [32] did not report any significant association between $\mathrm{Mg}$ and coronary artery calcification in HD patients. One explanation for this paradox might be the presence of toxins accumulating in CKD with a much stronger effect on the endothelium. One example is asymmetric dimethyl arginine $[33,34]$, which predicts cardiovascular events in $\mathrm{CKD} / \mathrm{HD}$ patients. In addition, despite an increase in total serum $\mathrm{Mg}$ with decreasing kidney function, the biologically active form which constitutes approximately $60 \%$ of total plasma $\mathrm{Mg}$ concentration is often lower in HD patients than in the general population, partially through complexing of $\mathrm{Mg}$ with phosphate and other anions [35]. In dialysis, patient's serum $\mathrm{Mg}$ is largely dependent on the ion concentration in the dialysate, poorly reflecting the status of this largely intracellular cation [36]. A Mg deficit, not expressed in serum $\mathrm{Mg}$ levels, might impair endothelial function contributing to renal injury and CVD.

Extrapolating data from studies carried out in the general [37], CKD/ESRD populations [38-41] to the transplant population may be misleading. In fact, only a small retrospective study limited to patients with biopsy-proven CsA nephrotoxicity showed an association between 
hypomagnesemia and decreased graft survival in kidney transplant recipients [42]. On the other hand, a metaanalysis to assess the risk of adverse effects in 6,786 RTR on proton pump inhibitors (PPI) revealed that PPI use was not associated with significant risks of higher acute rejection, graft loss, or 1-year mortality, although the risk of hypomagnesemia increased significantly [43].

In some studies, the correlation between hypomagnesemia to CVD and mortality has not been confirmed. In 1,068 patients with advanced HF, serum $\mathrm{Mg}$ was not an independent risk factor for all-cause mortality [44]. Khan et al. [45] did not find any association between serum $\mathrm{Mg}$ concentrations, incident HTN, CVD, and all-cause mortality in 3,531 participants in the Framingham Heart Study. Mg intake was not correlated with reduced risk for CVD in females [45]. A significant positive association between serum $\mathrm{Mg}$ levels and dyslipidemia in HD patients was established [46]. In patients with CKD stage 3 and 4, hypomagnesemia and hypermagnesemia were both associated with increased mortality [47]. In another study hypermagnesemia, but not hypomagnesemia at the time of hospital admission was associated with increased 1 -year mortality among hospitalized patients [48]. Possible explanations for these somewhat contradictory results include case mix, sample size, differences in length of follow-ups, or publication bias. Moreover, CVD is a large spectrum multifactorial clinical entity. Thus, participants may have other unmeasured comorbidities or risk factors predisposing them to the development of CVD.

Given that serum Mg levels do not reflect the total body of $\mathrm{Mg}$ content, we can assume that low $\mathrm{Mg}$ levels are simply a marker of malnutrition. A cross-sectional study including $58 \mathrm{HD}$ patients reported a significant inverse correlation between serum $\mathrm{Mg}$ levels and C-reactive protein [49]. Low serum Mg levels in peritoneal dialysis patients were associated both with increased levels of C-reactive protein and poor nutritional status, contributing to increased mortality risk [50]. Interestingly, hypomagnesemia was not an independent risk factor for mortality in 353 Japanese HD patients but was associated with malnutrition [51]. Taken together, it is possible that low $\mathrm{Mg}$ levels may indicate poorer nutrition status that can be attributed to chronic inflammation or that hypomagnesemia is simply a marker of malnutrition, inflammation, and atherosclerosis syndrome, which is quite prevalent in CKD patients. Following a successful renal transplant, the patient's nutritional status improves and the inflammatory condition may completely disappear. Hypomagnesemia, which may be the result of chronic inflammation both in CKD and in CVD, or is just a reflection of poor nutritional status in chronic illness, is possibly the result of completely different mechanisms during the posttransplant period and, as such, has totally different implications.

Although hypomagnesemia is associated with negative outcomes in CKD/ESRD patients, it may reflect a better tubular graft function early posttransplant with an improved allograft survival in the long term. Low phosphate levels at 3 months and 1 year posttransplant in the low $\mathrm{Mg}$ group compared to the high $\mathrm{Mg}$ group, without any significant difference in PTH and calcium levels between the groups supports this hypothesis. Hypomagnesemia as well as hypophosphatemia early posttransplant may indicate a better tubular graft function. Beyond that, phosphate depletion can further enhance $\mathrm{Mg}$ loss by reducing $\mathrm{Mg}$ ion reabsorption in the DCT $[52,53]$.

Certain limitations should be considered when interpreting the results of this study. As an observational study performed retrospectively, we relied on data from a large data registry. Observational analysis of a data registry can establish associations but not causal relationships between the primary variables of interest and outcomes. Even though we adjusted for numerous variables, residual confounding parameters such as PPI use and assessment of proteinuria may still exist. The large number of patients involved, the long follow-up period and the standardization of treatment practices limit confounding. Furthermore, as a retrospective study, we chose the immunosuppressive agents to consider, possibly leading to inclusion bias. Nevertheless, these factors do not negate the relationship between hypomagnesemia to patient and graft survival, nor between the use of CNI and hypomagnesemia. Some might contend that the measurement of ionized and/or intracellular Mg levels may be a more reliable indicator of body $\mathrm{Mg}$ stores than the total Mg measure we used. Due to our study's design, we did not perform 31P nuclear magnetic resonance spectroscopy, the gold standard technique for measuring free $\mathrm{Mg}$. However, previous data have pointed to a correlation between total serum $\mathrm{Mg}$ levels and intracellular free Mg levels measured by nuclear magnetic resonance spectroscopy in hypomagnesemic subjects $(r=0.54 ; p<0.001)$ [54]. In addition, research has demonstrated that in RTR, Mg levels were lower compared to control subjects whether they were measured as plasma (total and ionized) levels or intracellular erythrocyte and platelet $\mathrm{Mg}$ concentrations [55]. In our analysis, we included a covariate for the coefficient of variation for $\mathrm{Mg}$ blood levels. We adopted this approach because large fluctuations in serum $\mathrm{Mg}$ level 
were associated with increased mortality in 20,438 hospitalized patients [56].

We found a stronger association between $\mathrm{Mg}$ and mortality compared to the association with graft loss. Furthermore, hypomagnesemia was associated with graft loss only when combining it with death as an outcome. Survival analysis takes into consideration overall followup time. Therefore, in the survival analysis we included patients who died during the follow-up period but excluded them from the multivariate analysis of the years following their death. In the graft survival multivariable analysis, we compared mean GFR. Given that the number of patients with graft loss is fairly small, it is possible that their effect on the overall mean was too small to be significant.

This study is the first to show that hypomagnesemia from 1 to 12 months posttransplant is associated with better patient and allograft survival rates up to 10 years posttransplant in a large cohort of RTR. This relationship remained significant even after adjusting for relevant clinical factors including baseline allograft function, presence of SGF, CNI trough levels, and coefficient of variation for CNI trough levels. The effects of CNI on graft outcome may be partially attributed to CNI-induced hypomagnesemia.

\section{Conclusion}

This paper further strengthens our previous findings about the association between early posttransplant hypomagnesemia and long-term allograft function. We believe that hypomagnesemia could serve as a biomarker of better tubular function early on and be a good predictor of long-term patient and allograft outcomes. Future research should seek to identify mechanisms by which hypomagnesemia protects the allograft.

\section{Statement of Ethics}

The study was approved by the local Ethics Committee at Brigham and Women's Hospital (protocol \#: 2013P002558). This retrospective review of patient data did not require written informed consent from participants in accordance with local/national guidelines.

\section{Conflict of Interest Statement}

The authors declare no conflicts of interest.

\section{Funding Sources}

There were no funding sources.

\section{Author Contributions}

Ofer Isakov: data analysis and writing; Bhanu K. Patibandla: data organization and analysis; Kenneth B. Christopher: review; Anil Chandraker: planning and review; Tammy Hod: planning, data analysis, writing, and review.

\section{Data Availability Statement}

The datasets used and/or analyzed during the current study are available from the corresponding author on reasonable request.

\section{References}

1 Vannini SD, Mazzola BL, Rodoni L, Truttmann AC, Wermuth B, Bianchetti MG, et al. Permanently reduced plasma ionized magnesium among renal transplant recipients on cyclosporine. Transpl Int. 1999;12(4) 244-9.

2 Sabbagh F, El Tawil Z, Lecerf F, Hulin A, Maurois P, Dartevelle P, et al. Impact of cyclosporine A on magnesium homeostasis: clinical observation in lung transplant recipients and experimental study in mice. Transplantation. 2008 Aug 15;86(3):436-44.

3 Van Laecke S, Van Biesen W. Hypomagnesaemia in kidney transplantation. Transplant Rev. 2015 Jul;29(3):154-60.

4 Liao F, Folsom AR, Brancati FL. Is low magnesium concentration a risk factor for coro-

Post-Transplant Hypomagnesemia nary heart disease? The atherosclerosis risk in communities (ARIC) study. Am Heart J. 1998 Sep;136(3):480-90.

5 Peacock JM, Folsom AR, Arnett DK, Eckfeldt JH, Szklo M. Relationship of serum and dietary magnesium to incident hypertension: the atherosclerosis risk in communities (ARIC) study. Ann Epidemiol. 1999 Apr;9(3): $159-65$.

6 He K, Liu K, Daviglus ML, Morris SJ, Loria $\mathrm{CM}$, Van Horn L, et al. Magnesium intake and incidence of metabolic syndrome among young adults. Circulation. 2006 Apr 4; 113(13):1675-82.

7 Ohira T, Peacock JM, Iso H, Chambless LE, Rosamond WD, Folsom AR. Serum and dietary magnesium and risk of ischemic stroke: the atherosclerosis risk in communities study. Am J Epidemiol. 2009 Jun 15;169(12):143744.

8 Massy ZA, Drüeke TB. Magnesium and outcomes in patients with chronic kidney disease: focus on vascular calcification, atherosclerosis and survival. Clin Kidney J. 2012 Feb;5(Suppl 1):i52-61.

9 Laurant P, Berthelot A. Influence of endothelium on $\mathrm{Mg}(2+)$-induced relaxation in noradrenaline-contracted aorta from DOCA-salt hypertensive rat. Eur J Pharmacol. 1994 Jun 13;258(3):167-72.

10 Wolf FI, Trapani V, Simonacci M, Ferré S, Maier JA. Magnesium deficiency and endothelial dysfunction: is oxidative stress involved? Magnes Res. 2008 Mar;21(1):58-64. 
11 Shechter M, Sharir M, Labrador MJ, Forrester J, Silver B, Bairey Merz CN. Oral magnesium therapy improves endothelial function in patients with coronary artery disease. Circulation. 2000 Nov 7;102(19):2353-8.

12 Pham PC, Pham PM, Pham SV, Miller JM, Pham PT. Hypomagnesemia in patients with type 2 diabetes. Clin J Am Soc Nephrol. 2007 Mar;2(2):366-73.

13 Sjogren A, Floren CH, Nilsson A. Magnesium deficiency in IDDM related to level of glycosylated hemoglobin. Diabetes. 1986 Apr; 35(4):459-63.

14 Resnick LM, Altura BT, Gupta RK, Laragh JH, Alderman MH, Altura BM. Intracellular and extracellular magnesium depletion in type 2 (non-insulin-dependent) diabetes mellitus. Diabetologia. 1993 Aug;36(8):767-70.

15 Rodriguez-Moran M, Guerrero-Romero F. Oral magnesium supplementation improves insulin sensitivity and metabolic control in type 2 diabetic subjects: a randomized double-blind controlled trial. Diabetes Care. 2003 Apr;26(4):1147-52.

16 Van Laecke S, Van Biesen W, Verbeke F, De Bacquer D, Peeters P, Vanholder R. Posttransplantation hypomagnesemia and its relation with immunosuppression as predictors of new-onset diabetes after transplantation. Am J Transplant. 2009 Sep;9(9):2140-9.

17 Cheungpasitporn W, Thongprayoon C, Harindhanavudhi T, Edmonds PJ, Erickson SB. Hypomagnesemia linked to new-onset diabetes mellitus after kidney transplantation: a systematic review and meta-analysis. Endocr Res. 2016 May;41(2):142-7.

18 Hayes W, Boyle S, Carroll A, Bockenhauer D, Marks SD. Erratum to: Hypomagnesemia and increased risk of new-onset diabetes mellitus after transplantation in pediatric renal transplant recipients. Pediatr Nephrol. 2017 May; 32(5):903-84.

19 Osorio JM, Bravo J, Pérez A, Ferreyra C, Osuna A. Magnesemia in renal transplant recipients: relation with immunosuppression and posttransplant diabetes. Transplant Proc. 2010 Oct;42(8):2910-3.

20 Augusto JF, Subra JF, Duveau A, Rakotonjanahary J, Dussaussoy C, Picquet J, et al. Relation between pretransplant magnesemia and the risk of new onset diabetes after transplantation within the first year of kidney transplantation. Transplantation. 2014 Jun 15; 97(11):1155-60.

21 June $\mathrm{CH}$, Thompson CB, Kennedy MS, Loughran TP Jr, Deeg HJ. Correlation of hypomagnesemia with the onset of cyclosporine-associated hypertension in marrow transplant patients. Transplantation. 1986 Jan;41(1):47-51.

22 Miura K, Nakatani T, Asai T, Yamanaka S, Tamada S, Tashiro K, et al. Role of hypomagnesemia in chronic cyclosporine nephropathy. Transplantation. 2002 Feb 15;73(3):340-
23 Hod T, Isakov O, Patibandla BK, Christopher KB, Hershkoviz R, Schwartz IF, et al. Posttransplantation hypomagnesemia as a predictor of better graft function after transplantation. Kidney Blood Press Res. 2020;45:982-95.

24 Verbeke F, Van Biesen W, Peeters P, Van Bortel LM, Vanholder RC. Arterial stiffness and wave reflections in renal transplant recipients. Nephrol Dial Transplant. 2007 Oct;22(10): 3021-7.

25 Mazzola BL, Vannini SD, Truttmann AC, von Vigier RO, Wermuth B, Ferrari P, et al. Longterm calcineurin inhibition and magnesium balance after renal transplantation. Transplant Int. $2003 \mathrm{Feb}$;16(2):76-81.

26 Nijenhuis T, Hoenderop JG, Bindels RJ. Downregulation of $\mathrm{Ca}(2+)$ and $\mathrm{Mg}(2+)$ transport proteins in the kidney explains tacrolimus (FK506)-induced hypercalciuria and hypomagnesemia. J Am Soc Nephrol. 2004 Mar; 15(3):549-57.

27 Gratreak BDK, Swanson EA, Lazelle RA, Jelen SK, Hoenderop J, Bindels RJ, et al. Tacrolimus-induced hypomagnesemia and hypercalciuria requires FKBP12 suggesting a role for calcineurin. Physiol Rep. 2020 Jan;8(1): e14316.

28 aL-Khursany I, Thomas TH, Harrison K, Wilkinson R. Reduced erythrocyte and leukocyte magnesium is associated with cyclosporin treatment and hypertension in renal transplant patients. Nephrol Dial Transplant. 1992; 7(3):251-5.

29 Asai T, Nakatani T, Tamada S, Kuwabara N, Yamanaka S, Tashiro K, et al. Activation of transcription factors AP-1 and NF-kappaB in chronic cyclosporine A nephrotoxicity: role in beneficial effects of magnesium supplementation. Transplantation. 2003 Apr 15; 75(7):1040-4.

30 Carvalho da Costa M, de Castro I, Neto AL, Ferreira AT, Burdmann EA, Yu L. Cyclosporin A tubular effects contribute to nephrotoxicity: role for $\mathrm{Ca} 2+$ and $\mathrm{Mg} 2+$ ions. Nephrol Dial Transplant. 2003 Nov;18(11):2262-8.

31 Mortazavi M, Moeinzadeh F, Saadatnia M, Shahidi S, McGee JC, Minagar A. Effect of magnesium supplementation on carotid intima-media thickness and flow-mediated dilatation among hemodialysis patients: a double-blind, randomized, placebo-controlled trial. Eur Neurol. 2013;69(5):309-16.

32 Tamashiro M, Iseki K, Sunagawa O, Inoue T, Higa S, Afuso $\mathrm{H}$, et al. Significant association between the progression of coronary artery calcification and dyslipidemia in patients on chronic hemodialysis. Am J Kidney Dis. 2001 Jul;38(1):64-9.

33 Schiffrin EL, Lipman ML, Mann JF. Chronic kidney disease: effects on the cardiovascular system. Circulation. 2007 Jul 3;116(1):85-97.

34 Stenvinkel P, Carrero JJ, Axelsson J, Lindholm B, Heimbürger O, Massy Z. Emerging biomarkers for evaluating cardiovascular risk in the chronic kidney disease patient: how do new pieces fit into the uremic puzzle? Clin J Am Soc Nephrol. 2008 Mar;3(2):505-21.
35 Navarro-Gonzalez JF, Mora-Fernandez C, Garcia-Perez J. Clinical implications of disordered magnesium homeostasis in chronic renal failure and dialysis. Semin Dial. 2009 JanFeb;22(1):37-44.

36 Nilsson P, Johansson SG, Danielson BG. Magnesium studies in hemodialysis patients before and after treatment with low dialysate magnesium. Nephron. 1984;37(1):25-9.

37 Tin A, Grams ME, Maruthur NM, Astor BC, Couper D, Mosley TH, et al. Results from the atherosclerosis risk in communities study suggest that low serum magnesium is associated with incident kidney disease. Kidney Int. 2015 Apr;87(4):820-7.

38 Kanbay M, Yilmaz MI, Apetrii M, Saglam M, Yaman H, Unal HU, et al. Relationship between serum magnesium levels and cardiovascular events in chronic kidney disease patients. Am J Nephrol. 2012;36(3):228-37.

39 Sakaguchi Y, Shoji T, Hayashi T, Suzuki A, Shimizu M, Mitsumoto K, et al. Hypomagnesemia in type 2 diabetic nephropathy: a novel predictor of end-stage renal disease. Diabetes Care. 2012 Jul;35(7):1591-7.

40 Van Laecke S, Nagler EV, Verbeke F, Van Biesen W, Vanholder R. Hypomagnesemia and the risk of death and GFR decline in chronic kidney disease. Am J Med. 2013 Sep;126(9): 825-31.

41 Sakaguchi Y, Fujii N, Shoji T, Hayashi T, Rakugi $\mathrm{H}$, Isaka $\mathrm{Y}$. Hypomagnesemia is a significant predictor of cardiovascular and noncardiovascular mortality in patients undergoing hemodialysis. Kidney Int. 2014 Jan;85(1): $174-81$.

42 Holzmacher R, Kendziorski C, Michael Hof man R, Jaffery J, Becker B, Djamali A. Low serum magnesium is associated with decreased graft survival in patients with chronic cyclosporin nephrotoxicity. Nephrol Dial Transplant. 2005 Jul;20(7):1456-62.

43 Boonpheng B, Thongprayoon C, Bathini T, Sharma K, Mao MA, Cheungpasitporn W. Proton pump inhibitors and adverse effects in kidney transplant recipients: a meta-analysis. World J Transplant. 2019 Jun 28;9(2):35-47.

44 Eichhorn EJ, Tandon PK, DiBianco R, Timmis GC, Fenster PE, Shannon J, et al. Clinical and prognostic significance of serum magnesium concentration in patients with severe chronic congestive heart failure: the PROMISE Study. J Am Coll Cardiol. 1993 Mar 1; 21(3):634-40.

45 Khan AM, Sullivan L, McCabe E, Levy D, Vasan RS, Wang TJ. Lack of association between serum magnesium and the risks of hypertension and cardiovascular disease. Am Heart J. 2010 Oct;160(4):715-20.

46 Nasri H, Baradaran A. Correlation of serum magnesium with dyslipidemia in maintenance hemodialysis patients. Acta Medica. 2004;47(4):263-5. 
47 Azem R, Daou R, Bassil E, Anvari EM, Taliercio JJ, Arrigain S, et al. Serum magnesium, mortality and disease progression in chronic kidney disease. BMC Nephrol. 2020 Feb 12;21(1):49.

48 Cheungpasitporn W, Thongprayoon C, Bathini T, Hansrivijit P, Vaitla P, Medaura J, et al. Impact of admission serum magnesium levels on long-term mortality in hospitalized patients. Hosp Pract. 2020 Mar 14;48(2):80-5.

49 Pakfetrat M, Malekmakan L, Roozbeh J, Haghpanah S. Magnesium and its relationship to C-reactive protein among hemodialysis patients. Magnes Res. 2008 Sep;21(3):16770.
50 Fein P, Suda V, Borawsky C, Kapupara H, Butikis A, Matza B, et al. Relationship of serum magnesium to body composition and inflammation in peritoneal dialysis patients. Adv Perit Dial. 2010;26:112-5.

51 Mizuiri S, Nishizawa Y, Yamashita K, Naito $\mathrm{T}$, Ono $\mathrm{K}$, Tanji C, et al. Hypomagnesemia is not an independent risk factor for mortality in Japanese maintenance hemodialysis patients. Int Urol Nephrol. 2019 Jun;51(6): 1043-52.

52 Wong NL, Quamme GA, O'Callaghan TJ, Sutton RA, Dirks JH. Renal tubular transport in phosphate depletion: a micropuncture study. Can J Physiol Pharmacol. 1980 Sep; 58(9):1063-71.

53 Dai LJ, Friedman PA, Quamme GA. Phosphate depletion diminishes $\mathrm{Mg} 2+$ uptake in mouse distal convoluted tubule cells. Kidney Int. 1997 Jun;51(6):1710-8.
54 Ryzen E, Servis KL, DeRusso P, Kershaw A, Stephen T, Rude RK. Determination of intracellular free magnesium by nuclear magnetic resonance in human magnesium deficiency. J Am Coll Nutr. 1989 Dec;8(6):580-7.

55 Allegra A, Corica F, Ientile R, Corsonello A, Sparacino V, Accettola F, et al. Plasma (total and ionized), erythrocyte and platelet magnesium levels in renal transplant recipients during cyclosporine and/or azathioprine treatment. Magnes Res. 1998 Mar;11(1):11-8.

56 Malinowska J, Małecka M, Ciepiela O. Variations in magnesium concentration are associated with increased mortality: study in an unselected population of hospitalized patients. Nutrients. 2020 Jun 19;12(6):1836. 